\title{
Coronaviruses in cattle
}

\author{
Jaka Jakob Hodnik ${ }^{1} \cdot$ Jožica Ježek ${ }^{1} \cdot J^{\prime}$ zoze Starič ${ }^{1}$ (D)
}

Received: 19 May 2020 / Accepted: 13 July 2020 / Published online: 17 July 2020

(C) Springer Nature B.V. 2020

\begin{abstract}
Bovine coronaviruses are spread all over the world. They cause two types of clinical manifestations in cattle either an enteric, calf diarrhoea and winter dysentery in adult cattle, or respiratory in all age groups of cattle. The role of coronaviruses in respiratory infections is still a hot topic of discussion since they have been isolated from sick as well as healthy animals and replication of disease is rarely successful. Bovine coronavirus infection is characterised by high morbidity but low mortality. The laboratory diagnosis is typically based on serological or molecular methods. There is no registered drug for the treatment of virus infections in cattle and we are limited to supportive therapy and preventative measures. The prevention of infection is based on vaccination, biosecurity, management and hygiene. This paper will cover epidemiology, taxonomy, pathogenesis, clinical signs, diagnosis, therapy, economic impact and prevention of coronavirus infections in cattle.
\end{abstract}

Keywords Bovine coronavirus $\cdot$ Calf diarrhoea $\cdot$ Winter dysentery $\cdot$ Bovine respiratory disease complex $\cdot$ Betacoronavirus

\section{Introduction}

Coronaviruses are a very relevant topic, especially at this time when we are facing a severe acute respiratory syndrome coronavirus 2 (SARS-CoV-2) pandemic, which has elucidated how little we still know about these microorganisms and their spread from animals to humans (Bojkova et al. 2020). This review paper provides a complete overview of the essential current information on bovine coronaviruses' epidemiology, taxonomy, pathogenesis, clinical signs, diagnosis, therapy and prevention. It also provides information on the economic relevance of bovine coronavirus infections and a description of Norway's control programme for the limitation of their spread.

\section{The virus and taxonomy}

Bovine coronaviruses (BCoV) are single-stranded positivesense RNA viruses with a lipid envelope. Coronaviruses are spherical and got their name from the spike glycoproteins protruding from their envelope resembling a solar corona

Jože Starič

joze.staric@vf.uni-lj.si

1 Veterinary Faculty, Clinic for Reproduction and Large Animals Section for Ruminants, University of Ljubljana, Ljubljana, Slovenia
(Bárcena et al. 2009). They have five major structural proteins: hemagglutinin-esterase protein (HE), spike glycoprotein $(\mathrm{S})$, small membrane protein (E), membrane protein $(\mathrm{M})$ and nucleocapsid protein (N) (Suzuki et al. 2020), with the S and HE proteins being crucial for the virus to enter host cells and induce an immune response (Saif 2010; Ellis 2019). The N protein is most homologous between different $\mathrm{BCoVs}$ and is used for molecular diagnosis (Cho et al. 2001a; Park et al. 2006).

Bovine coronaviruses belong to the order Nidovirales, family Coronaviridae, subfamily Orthocoronavirinae, genus Betacoronavirus and subgenus Embecovirus. The genus Betacoronavirus is important for humans as well, as it contains one of the common cold viruses (human coronavirus OC43) and viruses associated with epidemics of severe acute respiratory syndrome-related coronavirus (HCoV-SARS) and Middle East respiratory syndrome-related coronavirus (MERS-CoV) as well as the severe acute respiratory syndrome coronavirus 2 (SARS-CoV-2), responsible for the current disastrous pandemic (ICTV 2019). A close relation of different coronaviruses explains the potential for zoonotic infections. Since 2008, bovine coronaviruses are no longer a distinct species. They have been merged into one species called Betacoronavirus 1 together with other human, swine, horse and dog coronaviruses (human enteric coronavirus; human coronavirus OC43; porcine hemagglutinating encephalomyelitis virus; equine coronavirus; canine respiratory coronavirus), and others were added later (Fig. 1). The change was 
justified because insufficient demarcation in the replicase $1 \mathrm{ab}$ domains is present (at least 10\%) to warrant a separate species (de Groot et al. 2008). Thus, BCoVs are now regarded as hostrange variant or quasispecies. Scientists have also identified a group of bovines like coronaviruses that cause similar clinical signs in other domestic and wild ruminants, which could serve as a reservoir for cattle infection and vice versa (Amer 2018).

\section{Epidemiology}

BCoVs are widespread all over the world (Boileau and Kapil 2010; Toftaker et al. 2017). Winter dysentery was typically reported in colder regions but new reports have documented episodes in warmer seasons (summer in Korea) or in tropical countries like Thailand, Brazil and Cuba (Barrera Valle et al. 2006; Park et al. 2006; Takiuchi et al. 2009; Ribeiro et al. 2016; Singasa et al. 2017). They can be divided into two groups based on clinical signs. The coronaviruses that were isolated from calves and cattle with diarrhoea are referred to as enteric $\mathrm{BCoV}(\mathrm{EBCoV})$ and those that were isolated from animals with respiratory clinical signs as respiratory $\mathrm{BCoV}$ $(\mathrm{RBCoV})$. Enteric $\mathrm{BCoV}$ can be further subdivided into $\mathrm{EBCoV}$ that cause diarrhoea in calves (EBCoV-CD) and those that cause winter dysentery in adult cattle (EBCoVWD) (Boileau and Kapil 2010).

BCoVs belong to one serotype (Takahashi et al. 1983; Saif 2010) but can be differentiated using molecular and antigenic methods; however, no distinct separating marker between clinical syndromes was identified (Zhang et al. 1994; Tsunemitsu and Saif 1995; Fukutomi et al. 1999; Hasoksuz et al. 2002; Kanno et al. 2007). The genetic sequences tend to cluster according to the geographical region of detection rather than the clinical picture (Park et al. 2006; Bidokhti et al. 2012; Beuttemmuller et al. 2017). A bigger difference was also observed between older and newer isolates than between isolates from different clinical syndromes (Zhang et al. 2007; Saif 2010). Furthermore, the same clinical picture was observed in calves experimentally infected with isolates from all three clinical syndromes of BCoV (Cho et al. 2001a; Bidokhti et al. 2012). They also provide some degree of cross-immunity, with no clinical signs and only virus shedding detected upon reinfection (El-Kanawati et al. 1996; Cho et al. 2001a). Therefore, it is speculated that clinical signs are not the result of infection with specific $\mathrm{BCoV}$ strain but of other circumstances at the time of infection such as stress, temperature and host health (Bidokhti et al. 2012; Suzuki et al. 2020).

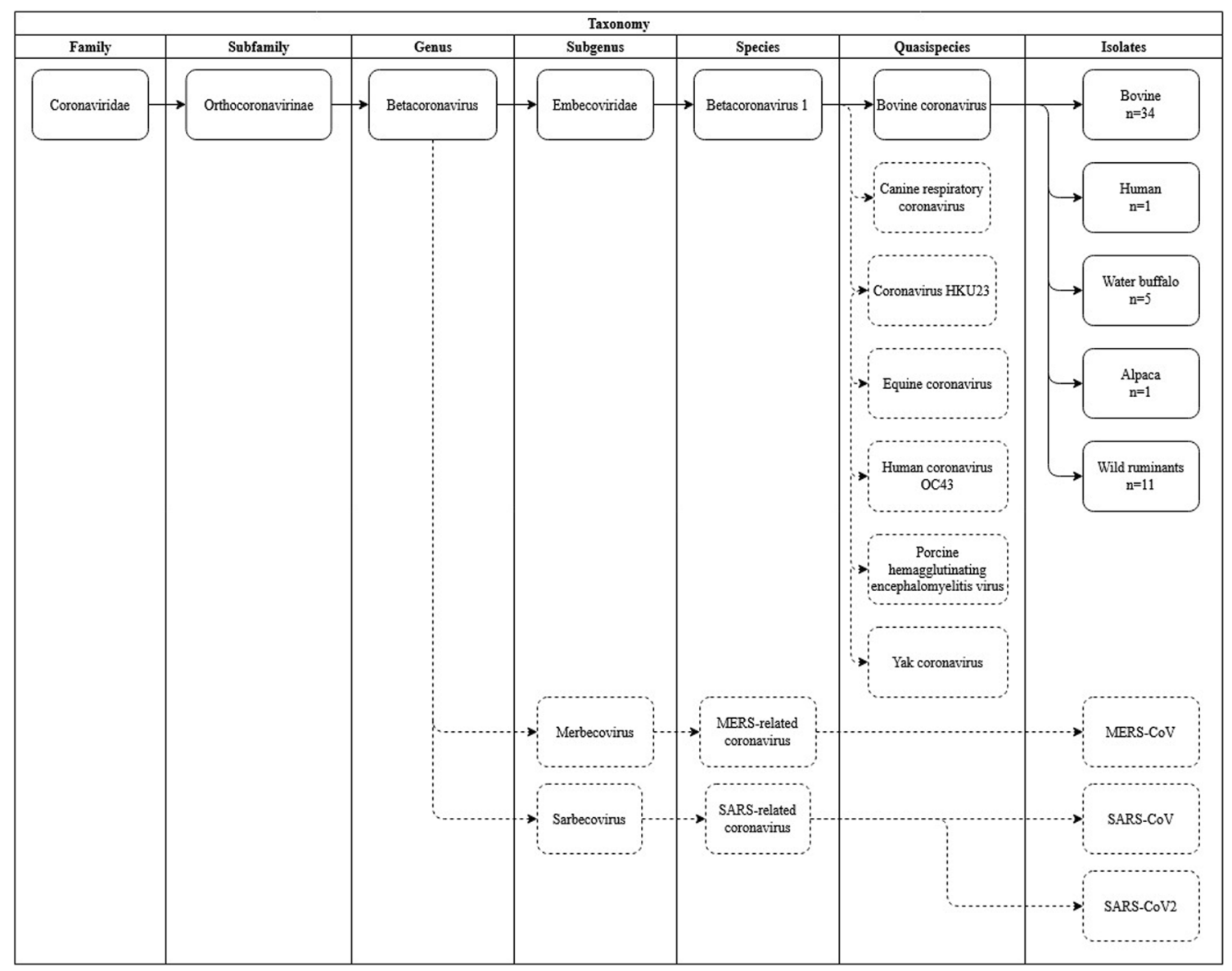

Fig. 1 Taxonomy of bovine coronavirus and its relation to SARS and MERS coronavirus 


\section{Pathogenesis}

Animals become infected with $\mathrm{BCoV}$ through the faecal-oral route or inhalation of aerosol (Thomas et al. 2006; Saif 2010; Oma et al. 2016). BCoVs enter the cell by binding to its membrane receptors (N-acetyl-9-O-acetylneuraminic acid) with the $\mathrm{S}$ protein, more specifically the $\mathrm{S} 1$ part, which forms the bulb. The virus gains entry into the cell by cleavage of the $\mathrm{S}$ protein by cellular trypsin-like proteases. The $\mathrm{S} 2$ part, which forms the stem of the protein, mediates the fusion of the virus with the host cell membrane (Popova and Zhang 2002). Whether the initial replication takes place in the respiratory (nasal turbinates, trachea and lungs) or the gastrointestinal tract (enterocytes) is still a matter of debate. With one side, claiming that the initial replication takes place in the respiratory tract and large quantities of virus protected by mucus are then swallowed to infect the intestine (Saif 2010; Oma et al. 2016), while the other side claims that the gastrointestinal tract is infected first and the virus reaches the respiratory tract with viraemia (Park et al. 2007; Boileau and Kapil 2010). Whatever the primary site of replication is, $\mathrm{BCoVs}$ are shed both in faeces and in nasal secretions (Cho et al. 2001a; Park et al. 2007). The duration of virus shedding can be quite extensive, up to 932 days post-infection detected with nested PCR in nasal discharge and 1058 days in faeces, as shown by Kanno et al. (2018). The role of chronically/subclinically infected animals is still debated because detection of the virus is common in clinically healthy adults and calves (Crouch et al. 1985; Cho et al. 2001a; Bartels et al. 2010; Coura et al. 2015). The most common route of disease transmission is from dam to calf or between calves. Between herds, infections occur with the purchase of new animals or with contaminated fomites (Oma et al. 2016; Oma et al. 2018). Dogs have also been suggested as carriers (Erles et al. 2003; Boileau and Kapil 2010). BCoV affects the whole gastrointestinal tract starting in the duodenum then spreading to the large intestine causing villous atrophy and other mucosal lesions (Mebus et al. 1973; Langpap et al. 1979; Park et al. 2007). In the respiratory tract, it causes interstitial pneumonia and epithelial damage on nasal turbinates, trachea and lungs (Park et al. 2007; Oma et al. 2016; Kalkanov et al. 2019).

\section{Clinical signs}

\section{Calf diarrhoea}

$\mathrm{BCoV}$ causes necrotic enterocolitis with loss of villous length, which results in malabsorption diarrhoea (Mebus et al. 1973; Langpap et al. 1979; Park et al. 2007). Morbidity is high while mortality can vary depending on age and immunity (Alfieri et al. 2018). The virus can cause haemorrhagic diarrhoea in calves. Most calves have yellow liquid diarrhoea with mucus and blood clots, dehydration, hypothermia and depression (Fig. 2). Reduced feed intake and electrolyte loss can result in metabolic acidosis and hypoglycaemia (Gomez and Weese 2017). In severe cases, fever, recumbence and death can also occur. Some calves may have additional respiratory signs (Mebus et al. 1973; Boileau and Kapil 2010). Most are affected between 3 and 21 days of age (Saif and Heckert 1990). The incubation period is 1-7 days (Mebus et al. 1973; Cho et al. 2001a). Clinical signs last for 3-6 days (Gomez and Weese 2017). Calves spread the virus with both faeces and nasal secretions (Cho et al. 2001a). The disease is self-limiting (Alfieri et al. 2018). BCoV can be found in both healthy and sick calves (Bartels et al. 2010; Coura et al. 2015). In a Uruguayan study, they found a seasonal pattern, with the winter months (average temperature $<13{ }^{\circ} \mathrm{C}$ ) having a higher frequency of detection of $\mathrm{BCoV}$ in calves (odds ratio: 9.05; 95\% CI: 2.77-29.53) (Castells et al. 2019).

\section{Winter dysentery}

In adult cattle, $\mathrm{BCoV}$ infection is characterised by epizootic outbreaks of self-limiting watery diarrhoea with the presence of blood, fever, depression, dehydration, anorexia, colic and drop in milk yield (Fig. 2) (Takahashi et al. 1983; Jactel et al. 1990; Natsuaki et al. 2007; Boileau and Kapil 2010; Akgül et al. 2013; Abuelo and Perez-Santos 2016). In severe cases, anaemia may occur because of blood loss (Natsuaki et al. 2007). The virus can be detected in both faeces and nasal secretions (Abuelo and Perez-Santos 2016). Naïve, dairy cows in the postpartum period are the most affected (Natsuaki et al. 2007). Incidentally, Ribeiro et al. (2016) have diagnosed a case of winter dysentery in pasture steers in Brazil. Concurrent respiratory signs have also been observed (Jactel et al. 1990; Akgül et al. 2013; Abuelo and Perez-Santos 2016). The incubation period is 2-8 days (Boileau and Kapil 2010). Morbidity is very high, up to $100 \%$, but mortality is low, less than 2\% (Jactel et al. 1990; Gagea et al. 2006; Takiuchi et al. 2009). Animals respond well to supportive treatment and usually recover in 2-3 days (Akgül et al. 2013). The episode will usually pass in 1-2 weeks depending on herd size and previous exposure to $\mathrm{BCoV}$. Episodes of winter dysentery were historically associated with colder regions and the onset of cold weather (cold stress), but new reports suggest that this is not the case with episodes in warmer seasons or in tropical countries (Barrera Valle et al. 2006; Park et al. 2006; Takiuchi et al. 2009; Ribeiro et al. 2016; Singasa et al. 2017). Park et al. (2006) speculate that this could be attributed to the absence of receptor-destroying enzyme (RDE) which they observed in the warmer season isolates and could lead to enhanced virulence or survivability in warmer environments. Lesions are similar to those seen in calf diarrhoea, mainly localised to the colon (Natsuaki et al. 2007). It is suspected that adult cattle are carriers of $\mathrm{BCoV}$ and that clinical signs emerge due to 
Fig. 2 Clinical signs and economic impact of bovine coronaviruses on cattle through their lifetime

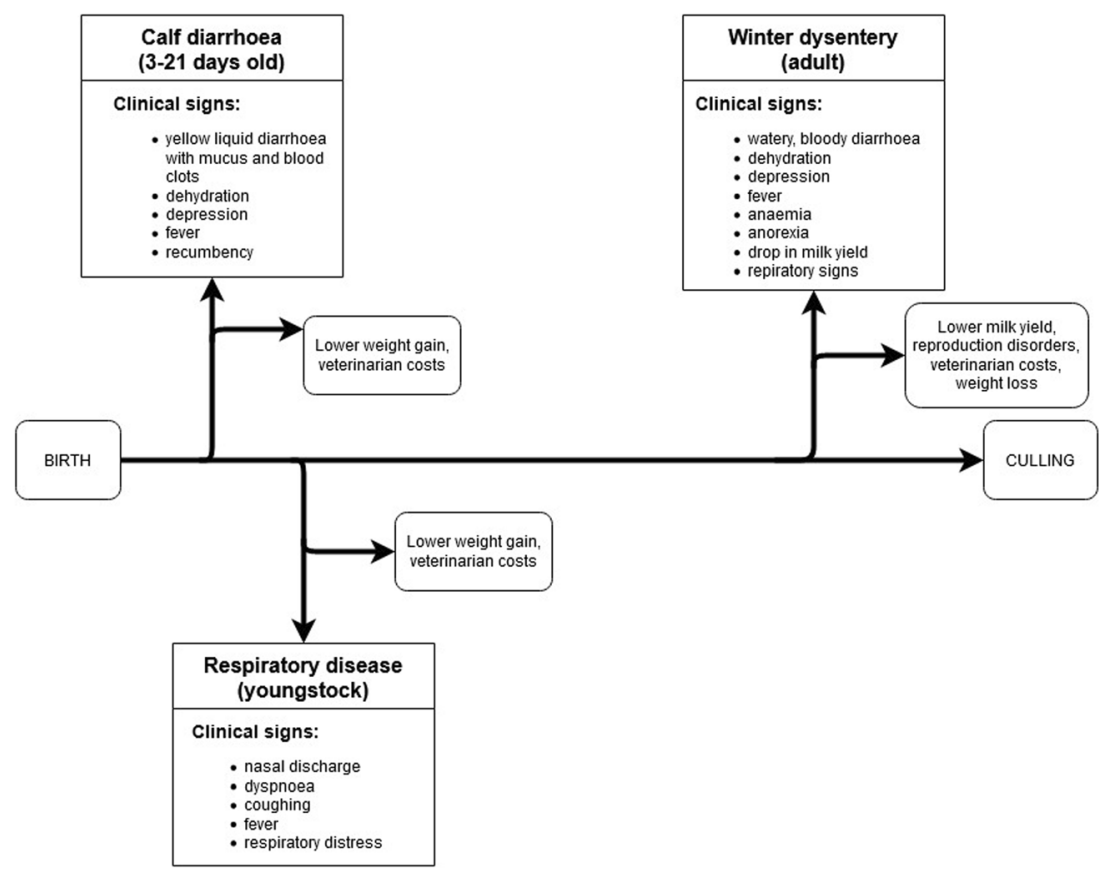

environmental stressors (Jactel et al. 1990; Abuelo and PerezSantos 2016).

\section{Respiratory BCoV}

$\mathrm{BCoV}$ has been isolated and detected in many outbreaks of respiratory disease in cattle of all ages (Heckert et al. 1990; Saif 2010; Decaro et al. 2008). Clinical signs include nasal discharge, dyspnoea, coughing, fever and respiratory distress (Fig. 2) (Saif 2010). However, controversy exists whether $\mathrm{BCoV}$ is also associated with bovine respiratory disease complex (BRDC). The controversy is based on the fact that many studies have isolated $\mathrm{BCoV}$ from feedlot cattle with clinical signs of BRDC and no or limited co-infection with other respiratory pathogens (Storz et al. 2000a; Lin et al. 2000; Lathrop et al. 2000; Cho et al. 2001b; Thomas et al. 2006; Paller et al. 2017), while others have achieved the same in clinically healthy cattle (Crouch et al. 1985; Heckert et al. 1990; Hasoksuz et al. 1999; Workman et al. 2019). However, most of the first studies have also identified seroconversion. Seroconversion protected animals from severe BRDC clinical signs and treatment in subsequent infections (Martin et al. 1998; Lin et al. 2000; Cho et al. 2001b; Plummer et al. 2004). Some studies did not confirm this association (Heckert et al. 1990; Workman et al. 2019). Few studies have confirmed BCoV in the lungs (McNulty et al. 1984; Storz et al. 2000a; Park et al. 2007; Paller 2019). Still, BCoV could be the factor that opens the floodgates for secondary bacterial infection. Storz et al. (2000b) have confirmed infections with BCoV and Pasteurella using Evan's criteria for causation. Ellis (2019), however, argues that the presence of $\mathrm{BCoV}$ in sick animals is not enough and a connection between virus load and clinical symptoms should be further investigated to confirm causality. Additionally, the evidence demonstrating Koch's postulates is scant and unsystematic (Ellis 2019). However, BCoVs should not be dismissed as a respiratory pathogen but should rather still be considered as a piece of the puzzle in the multifactorial aetiology of BRDC until proven otherwise.

\section{Diagnosis}

Infection with $\mathrm{BCoVs}$ can be suspected based on history, clinical presentation and age of the animal in enteric cases. Differential diagnoses include BVDV, Schmallenberg virus infection, Salmonella spp., Clostridium perfringens infection (enterotoxaemia), fasciolosis, nematodiasis and some intoxications in adult cattle and BVDV, rotavirus, enterotoxigenic Escherichia coli, Cryptosporidium parvum, coccidiosis, Salmonella spp., Clostridium perfringens infection (enterotoxaemia), giardiasis, nematodiasis and some intoxications in calves (Boileau and Kapil 2010; Sedda and Rogers 2013; Heller and Chigerwe 2018). For the definitive diagnosis, $\mathrm{BCoV}$ infection must be confirmed using laboratory assays like electron microscopy, virus isolation, serological or molecular methods. Rapid lateral flow immunoassay tests are also useful for cow-/calf-side testing (Kleina et al. 2008; Icen et al. 2013). Nasal swabs, tracheobronchial lavage, probang cups and faecal samples are used in live animals. It must be noted that the shedding of $\mathrm{BCoVs}$ is high at the time of initial infection and then stops or shifts to an 
intermittent shedding pattern (Coura et al. 2015; Oma et al. 2016). At necropsy trachea, nasal turbinates, lungs and the spiral colon are the samples of choice (Boileau and Kapil 2010). Oma et al. (2016) also detected virus RNA in mesenteric lymph nodes. Electron microscopy is hindered by low sensitivity (Saif 2010). For the isolation of BCoV either from enteric or respiratory samples, a cloned line of human rectal tumour (HRT)-18 cell cultures are used; however, the process is fastidious (Saif 2010; Ellis 2019). For the detection of virus antigens in tissues, immunofluorescent or immunohistochemical staining has proven to be effective (Boileau and Kapil 2010). To judge the serologic response of animals, virus neutralisation, hemagglutination inhibition (HI) tests and enzyme-linked immunosorbent assay (ELISA) are performed. Because seroconversion in cattle is common, pairedsamples are preferred (Saif 2010; Workman et al. 2019). Antigens in faeces and nasal swabs are detected using antigen-capture ELISA. However, molecular methods are more sensitive and have become widely used. They include RT-PCR, nested RT-PCR, real-time RT quantitative (q) PCR assays and genome sequencing (Saif 2010; Bidokhti et al. 2012; Kanno et al. 2018; Paller et al. 2017; Workman et al. 2019). The $\mathrm{N}$ protein gene is used for $\mathrm{BCoV}$ detection and $\mathrm{S}$ glycoprotein sequence for epidemiologic investigation and virus differentiation (Cho et al. 2001a; Park et al. 2006; Bidokhti et al. 2012). The sensitivity of molecular methods could lead to false-positive results in biologically insignificant cases (Oma et al. 2016; Ellis 2019). Oma et al. (2016) have detected the shedding of the virus with RT-qPCR 5 weeks post-inoculation, but at 3 weeks post-challenge, none of the comingled naïve calves became infected. They were also unable to isolate the virus at this point.

\section{Treatment}

Because there is currently no effective treatment for viral diseases, we are limited to supportive therapy. In calf diarrhoea, this consists of fluid, glucose and electrolyte supplementation to counter dehydration, hypoglycaemia, electrolyte imbalance and acidosis. Calves also benefit from a warm and dry stall (Boileau and Kapil 2010).

Winter dysentery is usually a self-limiting disease. However, in advanced cases, oral or intravenous fluid therapy or in cases of severe dysentery blood transfusion are indicated. The use of non-steroidal anti-inflammatory drugs (NSAID) and anti-haemorrhagic agents is also described (Natsuaki et al. 2007; Abuelo and Perez-Santos 2016; Chigerwe and Heller 2018).

In the case of BRDC, antimicrobial treatment is still advised because the secondary bacterial infection is common. The administration of non-steroidal anti-inflammatory drugs has also proven beneficial (Boileau and Kapil 2010).

\section{Economic impact}

The economic impact of winter dysentery is substantial, especially in dairy herds. The drop in milk production can vary from 0 to $70 \%$ per outbreak compared with the daily milk yield before infection according to different studies (Takahashi et al. 1983; Jactel et al. 1990; Takiuchi et al. 2009; Akgül et al. 2013; Abuelo and Perez-Santos 2016; Toftaker et al. 2017). In a Swedish study, the loss was calculated to be $51 \mathrm{~L}$ per cow in the period from 7 days before and 19 days after a reported outbreak compared with an uninfected cow. Additional costs can be attributed to veterinary treatment, additional labour, weight loss and reproduction disorders (Fig. 2) (Toftaker et al. 2017). Feedlot calves that shed BECoV had $8.17 \mathrm{~kg}$ lower weight gain compared with nonshedding herd mates (Cho et al. 2001b). Despite the role $\mathrm{BRCoV}$ in BRDC not being defined, we can still assume that economic losses also occur in respiratory infections with BRCoV (Martin et al. 1998).

\section{Prevention}

The prevention of $\mathrm{BCoV}$ diseases is important to limit the use of antimicrobials and subsequently reduce the occurrence of antimicrobial resistance, increase the quality of animal products and animal welfare. The prevention of $\mathrm{BCoV}$ was historically based on vaccination, management and hygiene. There are registered multivalent vaccines for dams to limit the shedding of the virus and provide hyperimmune colostrum that provides passive protection of calves, which both can protect from or lessen the severity of $\mathrm{BCoV}$ diarrhoea in calves. Vaccination of dams has proven to be fairly effective in a Uruguayan study, with calves from unvaccinated dams having a 4.02 (95\% CI: 1.18-8.9) higher odds of shedding BCoV (Castells et al. 2019). The importance of adequate passive immunity cannot be overstated (Boileau and Kapil 2010). A modified live vaccine for oral vaccination of calves also exists for the prevention of diarrhoea (Boileau and Kapil 2010). There were also studies using an intranasal vaccine for $\mathrm{BCoV}$ in feedlot calves to limit the effect of BRDC (Plummer et al. 2004) and a vaccine against winter dysentery (Takamura et al. 2002). Metaphylactic antimicrobials are also used in the prevention of bacterial co-infections in BRDC (McVey 2009). Management, housing and biosecurity also play a crucial role (Boileau and Kapil 2010). BCoVs are susceptible to heat, detergents and disinfectants like sodium hypochlorite, chloramine T, povidone iodine, $70 \%$ ethanol, glutaraldehyde, quaternary ammonium compounds, phenolic compounds and formaldehyde (Sattar et al. 1989; Sattar and Springthorpe 1996). However, coronaviruses have been reported to survive well at low temperatures and high relative humidity. Their survival on surfaces is also long, up to $120 \mathrm{~h}$ 
(Duan et al. 2003) and even longer in organic medium (Geller et al. 2012).

Norway is to the authors' best knowledge the only country in the world that has implemented a control programme for BCoVs. It has a joined Bovine Respiratory Syncytial Virus and $\mathrm{BCoV}$ national, industry run control programme based on serological surveillance and the classification of herds (positive/negative) in place since 2016. The programme aims to reduce the occurrence of $\mathrm{BCoV}$ on herd level by protecting herds from infection through biosecurity measures. Herds with negative status and additional biosecurity measures are reworded financially (10\% increase in price for young stock and breeding animals). The cost of the control programme is sheared between the producers and the industry. Eligible samples are bulk tank milk, pooled first lactation cow milk and pooled serum samples from young stock older than 180 days to avoid maternal antibody interference. Beef herds test only young stock. The negative status is valid for 1 year. If a producer buys an animal from a positive herd, the status is automatically switched to positive. The biosecurity measures include separation of animals of different statuses, different transport vehicles, the building of loading areas, the provision of a sluice and clean clothes and footwear for visitors. They have also provided a hotline to report outbreaks of disease to limit further spread (Stokstad et al. 2020).

\section{Conclusion}

Coronaviruses are involved in the aetiology of three clinical syndromes in cattle. However, its role in BRDC still needs to be proven beyond a reasonable doubt. Future research should aim to further investigate the reasons for the occurrence of different clinical syndromes in animals infected with the same $\mathrm{BCoV}$ and the role of cattle in coronavirus transmission to humans. In the light of the recent coronavirus pandemic, it would also be crucial to know if cattle can become infected and transmit the new SARS-CoV-2.

Funding information The research programme group P4-0092 of the Veterinary Faculty, University of Ljubljana, funded by the Slovenian Research Agency supported this work.

\section{Compliance with ethical standards}

Conflict of interest The authors declare that they have no conflict of interest.

\section{References}

Abuelo A., Perez-Santos M., 2016. A winter dysentery (coronavirus infection) outbreak in a dairy herd in Galicia (northwestern Spain), Veterinary Record Case Reports, 4: e000328 https://doi.org/10. 1136/vetreccr-2016-000328
Akgül G., Mecitoğlu Z., Ertürk A., Çatik S., Temizel E.M., Gülyaz V., Gülaçti I., Özdemir S., Onat K., Șenlik B. and Șentürk S., 2013. Isolation of First Local Coranavirus from Cattle with Winter Dysentery in Turkey, Uludag University Journal Of The Faculty Of Veterinary Medicine, 32, 2, 63-69

Alfieri A.A., Ribeiro J., de Carvalho Balbo L., Lorenzetti E. and Alfieri A.F., 2018. Dairy calf rearing unit and infectious diseases: diarrhea outbreak by bovine coronavirus as a model for the dispersion of pathogenic microorganisms, Tropical Animal Health and Production, 50, 8, 1937-1940

Amer H.M., 2018. Bovine-like coronaviruses in domestic and wild ruminants, Animal Health Research Reviews, 19, 113-124.

Bárcena M., Oostergetel G.T., Bartelink W., Faas F.G., Verkleij A., Rottier P.J., Koster A.J. and Bosch B.J., 2009. Cryo-electron tomography of mouse hepatitis virus: Insights into the structure of the coronavirion, Proceedings of the National Academy of Sciences of the United States of America, 106, 2, 582-587

Barrera Valle M., Rodríguez Batista E., Betancourt Martell A., Frías Lepuroux M. T. and Brandão P., 2006. Short communication: First report in Cuba of bovine coronavirus detection in a winter dysentery outbreak, Spanish Journal of Agricultural Research, 4, 3, 221-224

Bartels C.J., Holzhauer M., Jorritsma R., Swart W.A. and Lam T.J., 2010. Prevalence, prediction and risk factors of enteropathogens in normal and non-normal faeces of young Dutch dairy calves, Preventive Veterinary Medicine, 93, 2-3, 162-169.

Beuttemmuller E.A., Alfieri A.F., Headley S.A. and Alfieri A.A., 2017. Brazilian strain of bovine respiratory coronavirus is derived from dual enteric and respiratory tropism. Genetics and Molecular Research, 16, 2, https://doi.org/10.4238/gmr16029580

Bidokhti M.R., Tråvén M., Ohlson A., Baule C., Hakhverdyan M., Belák S., Liu L. and Alenius S., 2012. Tracing the transmission of bovine coronavirus infections in cattle herds based on $\mathrm{S}$ gene diversity, The Veterinary Journal, 193, 2, 386-390

Boileau M.J. and Kapil S., 2010. Bovine Coronavirus Associated Syndromes, Veterinary Clinics of North America: Food Animal Practice, 26, 1, 123-146

Bojkova D., Klann K., Koch B. Widera M., Krause D., Ciesek S., Cinatl J. and Münch C., 2020. Proteomics of SARS-CoV-2-infected host cells reveals therapy targets, Nature, https://doi.org/10.1038/ s41586-020-2332-7

Castells M., Giannitti F., Caffarena R.D., Casaux M.L., Schild C., Castells D., Riet-Correa F., Victoria M., Parreño V. and Colina R., 2019. Bovine coronavirus in Uruguay: genetic diversity, risk factors and transboundary introductions from neighboring countries, Archives of Virology, 164, 11, 2715-2724

Chigerwe M. and Heller M.C., 2018. Diagnosis and Treatment of Infectious Enteritis in Adult Ruminants, Veterinary Clinics of North America.Food Animal Practise, 34, 1, 119-131

Cho K.O., Hasoksuz M., Nielsen P.R., Chang K.O., Lathrop S. and Saif L.J., 2001a. Cross-protection studies between respiratory and calf diarrhea and winter dysentery coronavirus strains in calves and RTPCR and nested PCR for their detection, Archives of Virology, 146, $12,2401-2419$

Cho K.O., Hoet A.E., Loerch S.C., Wittum T.E. and Saif L.J., 2001 b. Evaluation of concurrent shedding of bovine coronavirus via the respiratory tract and enteric route in feedlot cattle, America Journal of Veterinary Research, 62, 9, 1436-1441

Coura F.M., Freitas M.D., Ribeiro J., de Leme R.A., de Souza C., Alfieri A.A., Facury Filho E.J., de Carvalho A.Ú., Silva M.X., Lage A.P. and Heinemann M.B., 2015. Longitudinal study of Salmonella spp., diarrheagenic Escherichia coli, Rotavirus, and Coronavirus isolated from healthy and diarrheic calves in a Brazilian dairy herd, Tropical Animal Health and Production, 47, 1, 3-11

Crouch C.F., Bielefeldt Ohmann H., Watts T.C. and Babiuk L.A., 1985. Chronic shedding of bovine enteric coronavirus antigen-antibody 
complexes by clinically normal cows, Journal of General Virology, $66,7,1489-1500$

de Groot R.J., Ziebuhr J., Poon L.L., Woo P.C., Talbot P., Rottier P.J.M., Holmes K.V., Baric R., Perlman S. and Enjuanes L., 2008. Revision of the Family Coronaviridae. Taxonomic Proposal of the Coronavirus Study Group to the ICTV Executive Committee. Available at https://data.ictvonline.org/proposals/2008.085-122V. v4.Coronaviridae.pdf. Accessed on 6 Apr 2020

Decaro N., Campolo M., Desario C., Cirone F., D’Abramo M., Lorusso E., Greco G., Mari V., Colaianni M.L., Elia G., Martella V. and Buonavoglia C., 2008. Respiratory disease associated with bovine coronavirus infection in cattle herds in Southern Italy, Journal of Veterinary Diagnostic Investigation, 20, 1, 28-32

Duan S.M., Zhao X.S., Wen R.F., Huang J.J., Pi G.H., Zhang S.X., Han J., Bi S.L., Ruan L., Dong X.P. and SARS Research Team, 2003. Stability of SARS coronavirus in human specimens and environment and its sensitivity to heating and UV irradiation, Biomedical and Environmental Sciences, 16, 3, 246-255

El-Kanawati Z.R., Tsunemitsu H., Smith D.R. and Saif L.J., 1996. Infection and cross-protection studies of winter dysentery and calf diarrhea bovine coronavirus strains in colostrum-deprived and gnotobiotic calves, American Journal of Veterinary Research, 57, 48-53

Ellis J., 2019. What is the evidence that bovine coronavirus is a biologically significant respiratory pathogen in cattle? Canadian Veterinary Journal, 60, 2, 147-152

Erles K., Toomey C., Brooks H.W. and Brownlie J., 2003. Detection of a group 2 coronavirus in dogs with canine infectious respiratory disease, Virology, 310, 2, 216-223

Fukutomi T., Tsunemitsu H. and Akashi H., 1999. Detection of bovine coronaviruses from adult cows with epizootic diarrhea and their antigenic and biological diversities, Archives of Virology, 144, 997-1006

Gagea M.I., Bateman K.G., van Dreumel T., McEwen B.J., Carman S., Archambault M., Shanahan R.A. and Caswell J.L., 2006. Diseases and pathogens associated with mortality in Ontario beef feedlots, Journal of Veterinary Diagnostic Investigation, 18, 1, 18-28

Geller C., Varbanov M. and Duval R.E., 2012. Human coronaviruses: insights into environmental resistance and its influence on the development of new antiseptic strategies, Viruses, 4, 11, 3044-3068

Gomez D.E. and Weese J.S., 2017. Viral enteritis in calves, Canadian Veterinary Journal, 58, 12, 1267-1274

Hasoksuz M., Lathrop S.L., Gadfield K.L. and Saif L.J., 1999. Isolation of bovine respiratory coronaviruses from feedlot cattle and comparison of their biological and antigenic properties with bovine enteric coronaviruses, American Journal of Veterinary Research, 60, 10, $1227-1233$

Hasoksuz M., Sreevatsan S., Cho K.O., Hoet A.E., Saif L.J., 2002. Molecular analysis of the S1 subunit of the spike glycoprotein of respiratory and enteric bovine coronavirus isolates, Virus Research, $84,1-2,101-109$

Heckert R.A., Saif L.J., Hoblet K.H. and Agnes A.G., 1990. A longitudinal study of bovine coronavirus enteric and respiratory infections in dairy calves in two herds in Ohio, Veterinary Microbiology, 22, 2 3, 187-201

Heller M.C. and Chigerwe M., 2018. Diagnosis and Treatment of Infectious Enteritis in Neonatal and Juvenile Ruminants, Veterinary Clinics of North America.Food Animal Practise, 34, 1, $101-117$

Icen H, Arserim N.B., Isik N., Özkan C. and Kaya A., 2013. Prevalence of Four Enteropathogens with Immunochromatographic Rapid Test in the Feces of Diarrheic Calves in East and Southeast of Turkey, Pakistan Veterinary Journal, 33, 4, 496-499

ICTV Master Species List 2019.v1. https://talk.ictvonline.org/files/ master-species-lists/m/msl/9601/download Accessed on 6 Apr 2020
Jactel B., Espinasse J., Viso M. and Valiergue H., 1990. An Epidemiological Study Of Winter Dysentery In Fifteen Herds In France, Veterinary Research Communications, 14, 5, 367-379

Kalkanov I., Dinev I. and Zarkov I., 2019. Etiological and pathomorphological investigations in calves with coronaviral pneumoenteritis, Macedonian Veterinary Review, 42, 1, 43-49

Kanno T., Hatama S., Ishihara R. and Uchida I., 2007. Molecular analysis of the $\mathrm{S}$ glycoprotein gene of bovine coronaviruses isolated in Japan from 1999 to 2006, Journal of General Virology, 88, 1218-1224

Kanno T., Ishihara R., Hatama S. and Uchida I., 2018. A long-term animal experiment indicating persistent infection of bovine coronavirus in cattle, Journal of Veterinary Medical Science, 80, 7, 1134 1137

Kleina D, Kernb A., Lapanc G., Benetkad V., Möstld K., Hassle A., and Baumgartner W., 2008. Evaluation of rapid assays for the detection of bovine coronavirus, rotavirus A and Cryptosporidium parvum in faecal samples of calves. The Veterinary Journal, https://doi.org/10. 1016/j.tvj1.2008.07.016

Langpap T.J., Bergeland M.E. and Reed D.E., 1979 Coronaviral enteritis of young calves: virologic and pathologic findings in naturally occurring infections, American Journal of Veterinary Research, 40, 10, 1476-1478

Lathrop S.L., Wittum T.E., Brock K.V., Loerch S.C., Perino L.J., Bingham H.R., McCollum F.T. and Saif L.J., 2000. Association between infection of the respiratory tract attributable to bovine coronavirus and health and growth performance of cattle in feedlots, American Journal of Veterinary Research, 61, 9, 1062-1066

Lin X. Q., O'Reilly K. L., Storz J., Purdy C. W. and Loan R. W., 2000. Antibody responses to respiratory coronavirus infections of cattle during shipping fever pathogenesis. Archives of Virology, 145, 2335-2349

Martin S.W., Nagy E., Shewen P.E. and Harland R.J., 1998. The association of titers to bovine coronavirus with treatment for bovine respiratory disease and weight gain in feedlot calves, Canadian Journal of Veterinary Research, 62, 4, 257-261

McNulty M.S., Bryson D.G., Allan G.M. and Logan E.F., 1984. Coronavirus infection of the bovine respiratory tract, Veterinary Microbiology, 9, 425-434

McVey D.S., 2009. BRD research needs in the next 10-20 years. Animal Health Research Review, 10, 2, 165-167.

Mebus C.A., Stair E.L., Rhodes M.B. and Twiehaus M.J., 1973. Pathology of neonatal calf diarrhea induced by a coronavirus-like agent, Veterinary Pathology, 10, 1, 45-64

Natsuaki S., Goto K., Nakamura K., Yamada M., Ueo H., Komori T., Shirakawa H. and Uchinuno Y., 2007. Fatal Winter Dysentery with Severe Anemia in An Adult Cow, Journal of Veterinary Medical Science, 69, 9, 957-960

Oma V.S., Tråvén M., Alenius S., Myrmel M. and Stokstad M., 2016. Bovine coronavirus in naturally and experimentally exposed calves; viral shedding and the potential for transmission, Virology Journal, 13, 100, https://doi.org/10.1186/s12985-016-0555-x

Oma V.S., Klem T., Traven M., Alenius S., Gjerset B., Myrmel M. and Stokstad M., 2018. Temporary carriage of bovine coronavirus and bovine respiratory syncytial virus by fomites and human nasal mucosa after exposure to infected calves, BMC Veterinary Research, 14, 1, 22, https://doi.org/10.1186/s12917-018-1335-1

Paller T., 2019. Aetiology of bovine respiratory disease complex in calves and young cattle, (PhD thesis, University of Ljubljana), http:// knjiznica.vf.uni-lj.si/PortalGenerator/Document.aspx $? \mathrm{id}=250$. Accessed 20 Apr 2020

Paller T., Hostnik P., Pogačnik M. and Toplak I., 2017. The prevalence of ten pathogens detected by a real-time PCR method in nasal swab samples collected from live cattle with respiratory disease, Slovenia veterinary research, 54, 3, 101-107

Park S.J., Jeong C, Yoon S.S., Choy H.E., Saif L.J., Park S.H., Kim Y.J., Jeong J.H., Park S.I., Kim H.H., Lee B.J., Cho H.S., Kim S.K., 
Kang M.I. and Cho K.O., 2006. Detection and Characterization of Bovine Coronaviruses in Fecal Specimens of Adult Cattle with Diarrhea during the Warmer Seasons, Journal Of Clinical Microbiology, 44, 9, 3178-3188

Park S.J., Kim G.Y., Choy H.E., Hong Y.J., Saif L.J., Jeong J.H., Park S.I., Kim H.H., Kim S.K., Shin S.S., Kang M.I. and Cho K.O., 2007. Dual enteric and respiratory tropisms of winter dysentery bovine coronavirus in calves, Archives of Virology, 152, 10, 1885-900

Plummer P.J., Rohrbach B.W., Daugherty R.A., Daugherty R.A., Thomas K.V., Wilkes R.P., Duggan F.E. and Kennedy M.A., 2004. Effect of intranasal vaccination against bovine enteric coronavirus on the occurrence of respiratory tract disease in a commercial backgrounding feedlot, Journal of the American Veterinary Medical Association, 225, 5, 726-731

Popova R. and Zhang X., 2002. The Spike but Not the Hemagglutinin/ Esterase Protein of Bovine Coronavirus Is Necessary and Sufficient for Viral Infection, Virology 294, 222-236

Ribeiro J., Lorenzetti E., Alfieri A.F. and Alfieri A.A., 2016. Molecular detection of bovine coronavirus in a diarrhea outbreak in pasturefeeding Nellore steers in southern Brazil, Tropical Animal Health and Production, 48, 649-653

Saif L.J., 2010. Bovine Respiratory Coronavirus, Veterinary Clinics of North America: Food Animal Practice, 26, 2, 349-364

Saif L.J. and Heckert R.A., 1990. Enteric coronaviruses. In: L.J. Saif, K.W. Theft (eds), Viral diarrheas of man and animals. CRC Press, Boca Raton, Florida, 185-252

Sattar S.A. and Springthorpe V.S., 1996. Transmission of viral infections throughanimate and inanimate surfaces and infection control through chemical disin-fection. In: C. Hurst (ed), Modeling Disease Transmission and Its Prevention by Disinfection. Cambridge University Press, Cambridge, UK, 224-257

Sattar S.A., Springthorpe V.S., Karim Y. and Loro P., 1989. Chemical disinfection of non-porous inanimate surfaces experimentally contaminated with four human pathogenic viruses, Epidemiology and Infection, 102, 3, 493-505

Sedda L. and Rogers D. J., 2013. The influence of the wind in the Schmallenberg virus outbreak in Europe, Scientific reports, 3, 3361

Singasa K., Songserm T., Lertwatcharasarakul P. and Arunvipas P., 2017. Molecular and phylogenetic characterization of bovine coronavirus virus isolated from dairy cattle in Central Region, Thailand. Tropical Animal Health and Production, 49, 7, 1523-1529

Stokstad M., Klem T.B., Myrmel M., Oma V.S., Toftaker I., Østerås O. and Nødtvedt A., 2020. Using Biosecurity Measures to Combat Respiratory Disease in Cattle: The Norwegian Control Program for Bovine Respiratory Syncytial Virus and Bovine Coronavirus, Frontiers in Veterinary Science, https://doi.org/10.3389/fvets.2020. 00167. Accessed on 9.4.2020

Storz J., Purdy C.W., Lin X., Burrell M., Truax R.E., Briggs R.E., Frank G.H. and Loan R.W., 2000a. Isolation of respiratory bovine coronavirus, other cytocidal viruses, and Pasteurella spp from cattle involved in two natural outbreaks of shipping fever, Journal of the American Veterinary Medical Association, 216, 10, 1599-1604
Storz J., Lin X., Purdy C.W., Chouljenko V.N., Kousoulas K.G., Enright F.M., Gilmore W.C., Briggs R.E. and Loan R.W., $2000 \mathrm{~b}$. Coronavirus and Pasteurella Infections in Bovine Shipping Fever Pneumonia and Evans' Criteria for Causation, Journal of Clinical Microbiology, 38, 9, 3291-3298

Suzuki T., Otake Y., Uchimoto S., Hasebe A. and Goto Y., 2020. Genomic Characterization and Phylogenetic Classification of Bovine Coronaviruses Through Whole Genome Sequence Analysis, Viruses, 12, 2, 183. https://www.mdpi.com/1999-4915/ 12/2/183. Accessed on 6 Apr 2020

Takahashi F., Akashi H. and Inaba Y., 1983. Bovine Epizootic Diarrhea Resembling Winter Dysentery Caused by Bovine Coronavirus, Japan Agricultural Research Quarterly, 17, 3, 185-190

Takamura K., Matsumoto Y. and Shimizu Y., 2002. Field study of bovine coronavirus vaccine enriched with hemagglutinating antigen for winter dysentery in dairy cows, Canadian Journal of Veterinary Research, 66, 4, 278-281

Takiuchi E., Fernandes Barry A., Alfieri A.F., Filippsen P. and Alfieri A.A., 2009. An Outbreak of Winter Dysentery Caused by Bovine Coronavirus in a High-Production Dairy Cattle Herd from a Tropical Country, Brazilian Archives of Biology and Technology, $52,57-61$

Thomas C.J., Hoet A.E., Sreevatsan S., Wittum T.E., Briggs R.E., Duff G.C. and Saif L.J., 2006. Transmission of bovine coronavirus and serologic responses in feedlot calves under field conditions, American Journal of Veterinary Research, 67, 8, 1412-1420

Toftaker I., Holmøy I., Nødtvedt A., Østerås O., and Stokstad M., 2017. A cohort study of the effect of winter dysentery on herd-level milk production, Journal of Dairy Science, 100, 6483-6493

Tsunemitsu H. and Saif L.J., 1995. Antigenic and biological comparisons of bovine coronaviruses derived from neonatal calf diarrhea and winter dysentery of adult cattle, Archives of Virology, 140, 1303-1311

Workman A.M., Kuehn L.A., McDaneld T.G., Clawson M.L. and Loy J.D., 2019. Longitudinal study of humoral immunity to bovine coronavirus, virus shedding, and treatment for bovine respiratory disease in pre-weaned beef calves, BMC Veterinary Research, 15, 161, https://doi.org/10.1186/s12917-019-1887-8

Zhang X., Herbst W., Kousoulas K.G. and Storz J., 1994. Comparison of the $\mathrm{S}$ genes and the biological properties of respiratory and enteropathogenic bovine coronaviruses, Archives of Virology, $134,421-426$

Zhang X., Hasoksuz M., Spiro D., Halpin R., Wang S., Vlasova A., Janies D., Jones L.R., Ghedin E. and Saif L.J., 2007. Quasispecies of bovine enteric and respiratory coronaviruses based on complete genome sequences and genetic changes after tissue culture adaptation, Virology, 363, 1, 1-10

Publisher's note Springer Nature remains neutral with regard to jurisdictional claims in published maps and institutional affiliations. 